\section{Constructional Apraxia}

Brittney Moore and Andrew S. Davis

Department of Educational Psychology, Ball State University, Muncie, IN, USA

\section{Synonyms}

Constructional dyspraxia

\section{Definition}

Constructional (or construction) apraxia results in an inability to manipulate physical stimuli to construct or build a design. Some patients with construction apraxia may have isolated difficulties with construction depending on the task, while others may be unsuccessful in all construction tasks (Lezak et al. 2012). Construction apraxia is one of the most common conditions resulting from a lesion to the parieto-temporo-occipital association cortex in either hemisphere (Benton and Tranel 1993). Indeed, the most common deficits seen in patients with lesions in the nondominant hemisphere (usually the right) are those involving construction abilities and visual-spatial analysis (Blumenfeld 2002).

\section{See Also}

- Apraxia

- Visual-Motor Function

- Visual-Spatial Ability

\section{References and Readings}

Benton, A. L., \& Tranel, D. (1993). Visuoperceptual, visuospatial, and visuoconstructive disorders. In K. M. Heilman \& E. Valenstein (Eds.), Clinical neuropsychology (3rd ed.). New York: Oxford University Press.

Blumenfeld, H. (2002). Neuroanatomy through clinical cases. Sunderland: Sinauer Associates.

Lezak, M. D., Howieson, D. B., Bigler, E. D., \& Tranel, D. (2012). Neuropsychological assessment (5th ed.). New York: Oxford University Press. 